\section{Elicitation by a discriminative stimulus of water-reinforced behavior and drinking} in water-satiated rats

\author{
ALBERT WEISSMAN \\ Pfizer, Inc., Groton, Conn. 06340
}

A stimulus previously trained as an $\mathrm{S}^{\mathrm{D}}$ generated both water-reinforced responding and drinking when presented to rats satiated for water during the former $S^{\Delta}$ condition. The results could not be attributed to the passage of time inherent in the satiation criterion, nor to specific stimulus properties of the $S^{D}$.

It is a common observation that a rat satiated for food or water in a testing chamber often resumes eating or drinking when returned to his living cage. Similarly, a rat having access to food or water ad lib in his home cage frequently responds appropriately to a food- or water-reinforcement schedule when placed in a testing chamber. In an effort to specify one stimulus condition under which both water-reinforced behavior and drinking can be generated from the water-satiated rat, a protocol reported by Skinner (1938, p. 195) was modified and extended to a water-reinforcement situation and supported with control groups. Skinner described his initial experiment as follows: "A discrimination was established in which $\mathrm{S}^{\mathrm{D}}$ was a click. The reflex $\mathrm{sS}^{\Delta} \cdot \mathrm{R}$ was then reinforced continuously until the drive was so low that elicitation was interrupted. When the rat had not responded for several minutes, the click was presented. Except for extremely low degrees of hunger, the click was invariably followed by a response. The response no longer occurred in the presence of $\mathrm{S}^{\Delta}$, although it had been continuously reinforced, but it immediately occurred in the presence of $S^{D}$." Specifically, the present experiment was designed to demonstrate that a stimulus previously established as an SD for water-reinforced behavior can, when presented, generate such behavior and drinking in the "water-satiated" rat.

\section{SUBJECTS}

The Ss were 32 male Sprague-Dawley rats, tested in four groups of eight each. Each rat weighed approximately $225 \mathrm{~g}$ when his group began testing.

\section{APPARATUS}

Training and testing were accomplished in a Lehigh Valley Rat Rotor that housed each group of eight rats in separate, identical chambers. The chambers also served as living quarters between sessions. Dry food pellets were available to each rat at all times. Stimulus conditions were controlled with electromechanical circuitry. Each chamber periodically contained (1) a lever, which required a 13-g downward force for a response to register (each leverpress was converted by a pulse former to a 50 -msec pulse), (2) an electrically isolated dipper mechanism and reservoir, programmed to enable 5-sec presentation of a cup containing $0.1 \mathrm{ml}$ of water, (3) a pair of stimulus lamps of $2 \mathrm{~W}$ mounted above the water, both of which were activated by the pulsed leverpress, (4) a "houselight" of $15 \mathrm{~W}$, which served to define $\mathrm{S}^{\mathrm{D}}$ or $\mathrm{S}^{\Delta}$ conditions, and (5) a drinkometer connection to the grid floor and dipper, which enabled the recording of the first lick following reinforcement.

\section{PROCEDURE}

Group I

$C R F$ training. During a $3-\mathrm{h}$ session that followed $24 \mathrm{~h}$ of water deprivation, each of eight rats was first trained on CRF with the houselight on.

Discrimination training. For three subsequent 3-h sessions separated from one another by $21 \mathrm{~h}$, each rat was exposed to $\mathrm{SD}^{\mathrm{D}}$ (houselight on) $-\mathrm{S}^{\Delta}$ (houselight off) training. $\mathrm{SD}^{D}$ and $\mathrm{S}^{\Delta}$ alternated during this discrimination training phase: $\mathbf{S}^{D}$ was presented for 30 -sec intervals, during which all

\section{Table 1}

Responding During the First $\mathrm{S}^{\mathrm{D}}$ Presentation of the Test Session

\begin{tabular}{|c|c|c|c|c|c|}
\hline Group & $\begin{array}{l}\text { Discrimination } \\
\text { Training } \\
\text { Period }\end{array}$ & $\begin{array}{c}\mathbf{S}^{\mathbf{D}} \\
\text { Condition } \\
\text { During } \\
\text { Test Session } \\
\end{array}$ & $\begin{array}{c}\text { Incidence of } \\
\text { Respond- } \\
\text { ing During } \\
\text { First } \\
5 \mathrm{Min} \\
\text { of } \mathrm{S}^{\mathrm{D}} \mathrm{S}\end{array}$ & $\begin{array}{c}\text { Median } \\
\text { Latency } \\
\text { of First } \\
\mathbf{S D}^{\mathbf{f} \text { Response }} \\
\end{array}$ & $\begin{array}{l}\text { Median } \\
\text { Number of } \\
\text { Responses } \\
\text { During } \\
\text { First SD } \\
\text { e Period }\end{array}$ \\
\hline 1 & $\begin{array}{l}S^{D}=\text { Light } \\
S^{\Delta}=\text { Dark }\end{array}$ & Light & $7 / 8$ & $21 \mathrm{Sec} t$ & $26 t$ \\
\hline II & $\begin{array}{l}S^{D}=\text { Light } \\
S^{\Delta}=\text { Dark }\end{array}$ & $\begin{array}{l}\text { None: Dark- } \\
\text { ness Remains }\end{array}$ & $1 / 8^{*}$ & $>300 \mathrm{Sec}$ & 0 \\
\hline III & $\begin{array}{l}S^{D}=\text { Dark } \\
S^{\Delta}=\text { Light }\end{array}$ & Dark & $8 / 8$ & $12 \mathrm{Sect}$ & 33t \\
\hline IV & $\begin{array}{l}\text { None: Light } \\
\text { on Randomly }\end{array}$ & Light & $2 / 8^{* *}$ & $>300 \mathrm{Sec}$ & 0 \\
\hline
\end{tabular}

*The latency of the one responder was $240 \mathrm{sec}$

**The latencies of the two responders were 60 and $96 \mathrm{sec}$

+ Latencies and numbers of responses from Groups $I$ and $I I I$ were significantly different from those from Groups II and IV $(p<.002$, Mann-Whitney $U$ test). 

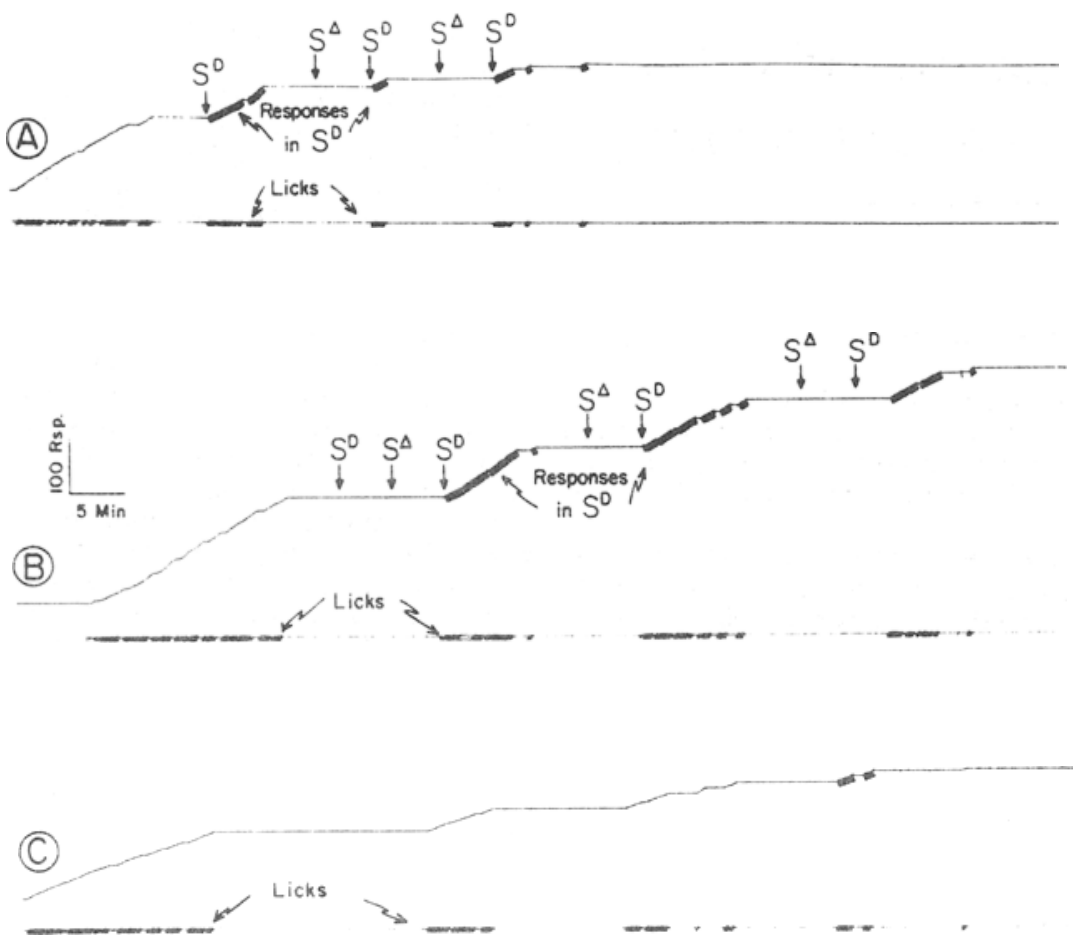

Fig. 1. Cumulative curves on the test day from rats in Groups I and II. (A) A typical record of a rat from Group I, which is also typical of rats in Group III. The initial component of the cumulative curve represents water-reinforced CRF responding in the former $S^{\Delta}$ condition. Following $5 \mathrm{~min}$ of no responding, $S^{D}$ was presented (first arrow) and CRF responding resumed. CRF responding in the $S^{D}$ condition is emphasized by signal marks on the cumulative curve. Following 5 min of no responding in $S^{D}, S^{\Delta}$ was reinstated and an additional 5 min of no responding occurred. Presentation of $S^{D}$ at that time (second $S^{D}$ arrow) generated CRF responding, and this behavioral cycle was repeated once more before responding ceased for a prolonged time. All reinforced responses were followed by licking, shown as signal marks on the baseline. (B) The record of the one rat from Group I that failed to respond within $5 \mathrm{~min}$ of the first $S^{D}$ presentation. Note that subsequent presentations of $S^{D}$ were followed with short latencies by responding. (C) A typical record of a rat from Group III. The former $S^{D}$ condition was never presented during the test session. Note that there is no tendency in this $S$ to respond when $5 \mathrm{~min}$ of no responding elapsed. The part of the cumulative curve identified with signal marks is the only part where responding would have occurred in $S^{D}$ had not $S^{\Delta}$ been sustained throughout this session.

factor affecting results from Group I. The procedure was identical to that of Group I, except that during "discrimination training," the houselight was randomly presented for 30 -sec intervals once during each 5-min period when reinforcement was unavailable but never during the 30 -sec period during which reinforcement was available. In this group, of course, no stimulus discrimination was possible during "discrimination training," but the temporal qualities of the schedule enabled the early development of FI behavior in some rats.

\section{RESULTS AND DISCUSSION}

The data from Groups I and III (Table 1; Fig. 1A) reveal that the stimulus condition formerly serving as an $\mathbf{S}^{\mathbf{D}-e l i c i t e d}$ water-reinforced latency of responding, when it occurred following $S^{D}$ presentation, was briefer and the number of responses was greater than after $\mathrm{s}^{\Delta}$ presentation.

With one negligible exception (Footnote $A$ in Table 1), rats in Group II failed to respond during the $5 \mathrm{~min}$ that followed $5 \mathrm{~min}$ of no responding (cf. Fig. 1C); data from this group show that there is little likelihood of water-reinforced responding shortly after $5 \mathrm{~min}$ of no responding in a CRF period, unless there is an appropriate stimulus change. Similarly, the data from Group IV indicate that a stimulus condition with which Ss have had experience but which has not served as an $\mathrm{S}^{\mathrm{D}}$ is also inadequate to elicit responding in water-satiated Ss.

A stimulus previously established as an $\mathrm{S}^{\mathrm{D}}$ for water-reinforced behavior has thus been shown to generate such behavior in water-satiated rats. Not only do rats respond under such conditions, they also consume the water reinforcement, as shown by drinkometer records [e.g., Fig. 1 (A and $B)]$. These data extend a finding using food-reinforced behavior briefly mentioned by Skinner (1938), the substance of which has been confirmed previously for food reinforcement in a study similar to the present one (Weissman, 1961).

When being transferred to a working chamber or to a home cage under conditions alluded to at the outset of this report, a $S$ is most certainly exposed to $\mathrm{SD}$ conditions. The emission of reinforced and consummatory behavior despite "satiation" in such circumstances may be regarded as a specific example of the phenomenon presently studied.

SD presentation, under the present protocol, cannot be said to elicit psychogenic polydipsia of the sort frequently described by Falk (for a review, see Falk, 1969), since the drinking that occurs when $S^{D}$ is presented is not sustained for prolonged times. Nevertheless, the present experiment serves to specify another example of stimulus conditions that are probably unrelated to physiological thirst but that can clearly generate drinking when drinking would otherwise have little probability of occurring.

\section{REFERENCES}

SKINNER, B. F. The behavior of organisms. New York: Appleton-Century-Crofts, 1938.

WEISSMAN, A. Stimulus dependence of satiation. Proceedings of the Meetings of the Eastern Psychological Association, Philadelphia, 1961.

FALK, J. L. Conditions producing psychogenic polydipsia in animals. Annals of the New York Academy of Sciences, $1969,157,569-589$. 